\title{
System-Based Coaching Technology Mechanism for the Development of Educational Systems
}

\author{
Yankun Ouyang ${ }^{1}$, Yu-Sheng $\mathrm{Su}^{2, *}$ a and Chenqi $\mathrm{Li}^{3}$ \\ 1 School of Transportation and Logistics, Southwest Jiaotong University, Chengdu 611756, China; \\ ouyyk@swjtu.cn \\ 2 Department of Computer Science and Engineering, National Taiwan Ocean University, \\ Keelung City 202, Taiwan \\ 3 School of Communication and Information Communication Engineering, University of Electronic Science \\ and Technology of China, Chengdu 611731, China; lichenqi@std.uestc.edu.cn \\ * Correspondence: ntoucsiesu@mail.ntou.edu.tw
}

Received: 6 December 2018; Accepted: 30 January 2019; Published: 12 February 2019

check for updates

\begin{abstract}
In order to further explore the performance of coaching technology in promoting the overall development of the education system, this paper applies the idea of system theory to deconstruct the five key elements and their interaction relations in the education system which affects the effect of education and training objectives. Meanwhile, the present situation and existing problems of each element are discussed including their influences for the system goal. The key analysis and exposition are made with the input and output of the core elements of the system to promote the overall coordinated development of the education system and improve the effectiveness. Based on the system theory we could conclude that this paper is of practical guiding value to promote the coordinated development of the key elements of the education system by using coaching technology, further to promote the overall evolution of the educational system and to promote the effective promotion of the overall goal of education and educating people.
\end{abstract}

Keywords: system theory; coaching technology; education system; coordinated development

\section{Introduction}

System theory is a science that researches the general rules of the development of nature, society, and human thinking, as well as various other systems [1-3]. System theory takes the system as the research object, and studies the relationship between the whole system and the elements that make up the system as a whole, so as to achieve the optimization of management. Therefore, the basic characteristics of integrity, relevance, purpose, and dynamics are the basic viewpoints of system theory [4]. The modern system theory came from the general system theory, cybernetics, and information theory in the 1940s, which is called the "old three theory" [5,6]. Besides, their commonality belongs to the "technical" level in the scientific structure, in other words, the main purpose of this theory is to solve specific technical problems. After the 1970s, the "new three theories" [7-9], which is the generic terms for dissipative structure theory, catastrophe theory, synergy and hyper-circulation theory, appeared and focused more on the factors and principles of system evolution. System theory believes that any system consists of several interconnected elements or subsystems with a specific structure and function. The state of synergy [10] between the various elements of system will affect the overall coordinated development of the system. Originally, system theory was used to solve complex large-scale engineering problems [11]. Later, according to holistic ideas, scientific methods and techniques of system science, system science was gradually applied to various fields of human life such as society, economy, nature, education, etc. 
Relatively speaking, the introduction of system science in the management of education started late, and the application is still not systematic. At present, some theoretical explorations and practical achievements apply systematic theory to the field of education. For example: the application of systematic theory of school education management system research, the construction of moral education system, ideological and political education, life education, mental health education, systematic research on innovative entrepreneurship education, system model research of higher vocational education, systematic research of family education, etc. In general, system theory has begun relevant researches and practices in different directions in education, and has achieved certain results, but the system application in education is still in a relatively early stage. The results are still relatively fragmented. Education system is a completely educational organization, which achieves a certain education purpose and function. For authors, in order to improve the sustainable development of education system, advanced education theory and technology should be adopted and continuous innovation should be carried out to make education conform to the development trend of the current society. At the same time, it can promote the development of the author's career in education. Coaching technology is a new management concept, which can meet the requirements of education management theory to some extent [12]. Due to the challenges raised by the world's new technological revolution to higher education, it is imperative to introduce system science and reform the ideas, techniques and methods of higher education management.

Coaching technology originated from the American sports in the 1970s [13]. The coacher helps people who want to grow to recognize and discover their own value and potential, besides, they can be a system of leadership and capacity development to achieve professional or life goals. Then, business executives are moving from coaching on the playground to corporate management. Thus, a new management coaching technology was born. After more than 30 years of development, coaching technology has gradually become a new and efficient management concept and technology, which is increasingly applied to many areas such as enterprise management, team performance, leadership improvement, career development, personal growth and family harmony. In addition, coaching technology has played an increasingly significant role in promoting organizational development and personal development [14]. Coaching technology is a systematic comprehensive application discipline integrating psychology, behavioral dynamics, management, sociology, brain science, quantum physics and other subjects. Coaching technology is based on high-quality processes of dialogue, guided by goals and results. Through a series of directional and strategic dialogues, coaching technology can gain insight into the mental model of the coach, help others discover potential, stimulate capacity, and eliminate interference [15]. Thus, exploring inward potentials, discovering outward possibilities, and supporting individuals and organizations to achieve external success through internal growth, so as to effectively achieve their goals effectively.

Coaching technology has been introduced and applied in more and more fields because of its effective support for the development of individuals and organizations. While in the field of education, there are also some explorations and practice, such as using coaching techniques to study the role of college student management, ideological and political education, psychological counseling, practical teaching, etc. [16]. Besides, it can research the cultivation of innovative entrepreneurial talents; study the application of coaching techniques to college students' career planning education, and use coaching techniques to develop the management of innovative schools. Furthermore, it can improve the growth of coaching parents, the effective quality of family education, students' motivation and interpersonal skills and so on.

At present, coaching technology is increasingly valued by the educational organization system, and more and more practical applications are available. However, the application is relatively fragmented and lacks systemic and holistic views, therefore, it plays a limited role.

The reminder of this paper is organized. The core elements of the education system and their relationships are presented in Section 2. In Section 3, we report the action mechanism of coaching technique on education system of this study. The conclusions are showed in Section 4. 


\section{The Core Elements of the Education System and Their Relationships}

\subsection{The Analysis of Characteristics of the Education System}

The education system contains all of the main features of a complex system. By analyzing the five core elements of education system, this paper explains the influence of coaching technology on all levels of education system, and further explores its effectiveness in education system.

(1) Target: The overall target of an education system is to educate people through every section, method and channel, which determine the overall direction and trends of the system.

(2) Integrity: An education system contains many sections and elements including educators, the educated, the education channel, the education environment etc, which forms the whole education system.

(3) Relevance: The elements and sections of the education system do not exist in isolation, but are related, interacted, restrict and coordinate with each other to affect the achievement of the goal of educating people.

(4) Dynamic: The key elements of the education system are in development and changing, which affects the dynamic changes of the whole system.

The application of system theory in education system is to use the concepts and methods of system theory to grasp the overall goal and principle of education, combine the operational characteristic and understand the core elements of the education system. Meanwhile, based on relationships of these factors, the effective support and promotion are done to improve the development and relationship of these elements, thus supporting the achievement of the overall goals of the education system.

\subsection{The Analysis of Core Elements and Current Status of the Education System}

Education system plays an important role on the development of people [17]. This paper mainly focuses on the education system which can affect the development of students. From the perspective of personal growth and development, the educational elements which may influence the development of a student mainly contains the social education system, school education, family education and influences from friends [18]. Among the school environment, the elements including the education management concept of school leader, the education methods of teachers, the education culture of the school and the relationships of students with their teachers, classmates and friends can influence the development of students subtly. Overall, the education system which can influence the development of students can be separated into five core elements including the education system, the school leaders, the teachers, the family education and the influences from friends, and these core elements will be analyzed one by one as follows.

\subsubsection{The Education System}

The social education system with its corresponding social values and social collective consciousness is an important social element influencing education. With the development and improvement of Chinese society, the education system is also reforming and developing, which leads to the guarantee and increment on educational investment. The popularity and fairness of education has been improved dramatically. In the last few years, with the reformation of College Entrance Examination, the drawback caused by this single evaluation mechanism has also been improved to some extent.

However, generally speaking, due to the huge pressure of enrollment and employment, this reformation on education system can hardly touch the foundation of exam-oriented education. The Chinese education system was once known as the "last bastion of the planned economy" due to the influence caused by planned economic system. Although promoting quality education has been claimed in Decision (1999) and planning outline (2010) issued by the Ministry of Education as 
one of the important tasks in order to improve the quality of education, the phenomenon in China's basic education that "teaching for the test and learning for the test" is still widespread due to the existence of deep institutional barrier. The test scores and the rate of enrollment are still the main criterion for teachers to evaluate students, school leaders to evaluate teacher and social to evaluate schools [19]. The quality education still floats on the surface form. As a result, the students coming from this education system are in lack of creativity and social adaptability.

\subsubsection{The School Leaders}

School education is an important way for human beings to inherit the achievement of civilization. The philosophy of school leaders on education and management determines the construction of school education and culture, the building of teach team and the effect of education directly [20]. Therefore, the educational philosophy, the personal qualities and the leadership of school leaders are the core element influencing the quality of education.

It cannot be denied that many school leaders are exploring scientific and effective method on education and management and also learning the advance experience of foreign countries. Many effective attempts have been done and some progress has been made. However, due to the social environment of blind competition and the traditional test-oriented education system, there are many difficulties and restriction on the development of education and the management of school education. Some school leaders also have problems such as closed education concept and lack of personal leadership ability, which has caused the school's education reform to lag behind [20]. The education evaluation mechanism is too single, unable to support the continuous growth of teachers, and it is difficult to stimulate the passion of teachers. At the same time, during the education process, too much pursuit of external performance and insufficient attention to the students' inner life growth cannot lead to an educational atmosphere and education mechanism to support the growth of teachers and students, which can affect the improvement of education quality.

\subsubsection{The School Teachers}

Teachers are the direct educators of students' learning and growth [21]. Han Yu used to describe the role of teachers in the education process: "teachers, so evangelism, teaching, and confusing!" The education and guidance of teachers will have an incalculable impact on academic development of students, literacy improvement, and even life development. Therefore, the teacher level and educational ability of the teacher group are very important elements influencing the achievement of educational goals.

At present, the vast majority of teachers engaged in early childhood education and primary and secondary education graduated from kindergarten normal schools or normal universities, and has theoretical foundation on education after the specialized education related to the teaching method. Most of the university teachers engaged in higher education who graduated from non-normal universities with master's degree or higher and have high-level specialist knowledge and abilities started their work on higher education only through short-term teacher qualification induction training. Many teachers chose the educational field for the reason of teaching and educating people and supporting the growth of others [22]. There are also many teachers choose the education because of the stability, social reputation and other characteristics of the teachers. Therefore, the basic concepts and abilities of education and the fundamental values of engaging in education career for different teachers are uneven.

Many teachers have worked hard on the post of teaching and educating people, paid a great deal of effort, and supported the growth and development of a large number of students [23]. At the same time, due to many reasons, such as imperfect education system and single teaching evaluation mechanism, many teachers themselves are faced with a lot of pressure and challenges which are difficult to break through in their daily lives, which not only affect their quality of life, but also affect their quality of teaching and educating people. For example, many teachers do not have a deep 
understanding of the essence of education, tending to attach great importance to teaching schoolwork and neglect educating students. Many teachers do not have sufficient understanding on the regularity and characteristics of life growth, lacking sufficient respect, understanding and trust for children's growth, lacking scientific and systematic education methods and so easily falling into the simple and rough single production line mode and produce homogeneous products which limits the development of children's individualization and characterization. Some teachers are lack of the passion for work and lack of sense of meaning and happiness, and even have job burnout. Some teachers ignore their words and deeds, and unconsciously bring their own problems into education to pass on negative values and affect students' physical and mental health.

Recently, the ministry of education issued the "Teachers education revitalization action plan 2018-2022", which takes strengthening the construction of teachers at all levels to an unprecedented new height [24].

\subsubsection{Family Education}

Family is the first and lifelong environment for children to grow up [25]. From the birth of a person, family environment begins to revolve around and has a profound impact on individual life development. The composition and mutual relations of family members, family atmosphere, family education concept, education method, especially the relationship between parents, will have an impact on the healthy growth of children all the time. The long-term shaping and influence of family education on children's character, psychology, habit, behavior and other aspects are beyond compare, which is enlightening, long-term, affective and infectious.

At present, Chinese families generally pay small attention to the quality of family education [26]. They do not know enough about the influence of the relationship between husband and wife and the parents themselves on the growth and development of their children, and they do not know enough about the laws of children's life growth, as a result, they often face with a lot of family education challenges and difficulties. For example, parents are not patient and respect enough to their children's growth and are eager to succeed. The disharmony between husband and wife causes long-term trauma to the child's heart. Some parents themselves do not learn and grow up, but only place their hopes on their children, which is difficult to set a good example for children. Some parents lack effective communication with their children, which lead to the lack of equal and harmonious parent-child relations, especially for children who are young and rebellious. Moreover, many parents are busy with their work and lack of time to accompany the children. Many parents are too dependent on school education and neglect the family education, thus they cannot cooperate with school effectively to support their children's growth and development together. All these situations have a subtle effect on the healthy growth of the child's body and mind.

\subsubsection{Peer Environment}

The mutual relationship and help between classmates are very important and influencing factor during their growth and study. The friendship between classmates is also the most precious spiritual wealth in their life [27].

With the development of economy, the goals of students' learning are no longer just to solve the basic survival problems. Moreover, the students are hoping to develop their talents and realize their own value. However, due to the influence of China's examination-oriented education system, many schools and teachers are still judging their children only with high scores [28]. Many parents also sign cramming school to their children because they do not want their children to lose at the starting line. Except for heavy load of homework, students also need to attend to the interest classes, which makes them very tied. Owing to many of the only children are the center of family, live in the family's excessive care and excessive expectations, they are very likely to form a strong self-awareness and competition, the concept of mutual comparison, blind competition of academic performance and family conditions [29]. What's more, many of them are lack of teamwork awareness, mutual assistance 
and support, weak sense of common growth, weak sense of responsibility, lack of synergy and ability. Hence, many students have not obtained the effective peer support and influence.

In summary, China's education system has achieved remarkable achievements after decades of exploration and development, especially under the reform of the education system. The ability of education to serve the social and economic development has been continuously enhanced. However, as the planning of Chinese education has not been fundamentally touched, the negative impact of exam-oriented education is still very serious. The core elements of the education system still have different levels of problems and limitations. The scientificity and effectiveness of the education system need to be systematically upgraded.

\subsection{The Interaction and Relationship of the Core Elements of the Education System}

The education system includes the external education system, the school leadership education management concept, the teacher teaching and educating methods, the family education method, and the students' peers influence. These factors interact and influence on the growth and development of the students. The relationship and interaction between them are shown in Figure 1.

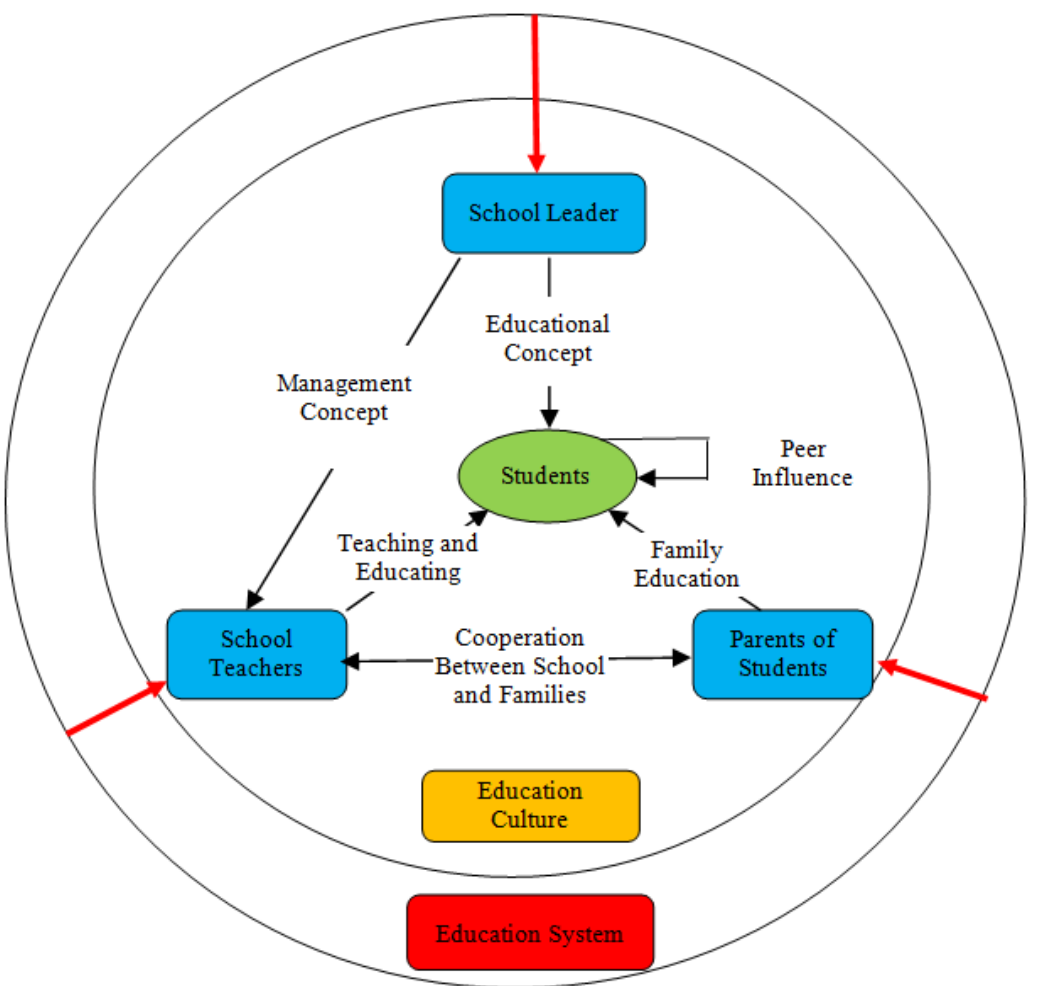

Figure 1. The core elements of education system and their interaction relations.

Education system plays a guiding or even decisive role for the education of the whole society to organize the implementation and to evaluate the effect of education. Because education system has effect on the social value orientation, not only education management concept is affected, but also the teacher's teaching value orientation, the family education ideas are affected. What's more, by means of a direct impact on school leaders, teachers, parents, education system can affect a child's growth and development in an indirect way during the process of education.

The management concept of school leaders directly determines the direction and form of school management, and determines the working status, growth and development of teachers. Moreover, the education concept of the school leadership directly determines not only the value orientation and cultural atmosphere of the whole education of the school, but also the overall quality of education. 
Due to that the teachers are education implementers who confront their children directly, the education concept and education method and the state of the teachers' own life stages can directly affect students' learning and growth and life development.

Family education plays an irreplaceable role in the process of education. Parents' education concept and their life states directly affect the formation and development of children's mental model. The mutual cooperation and support between family education and school education are very critical for the growth and development of children.

The peer influence, mutual support and teamwork, setting an example and growing together, are also very important supports to guide children's positive learning and growth.

Although the education system is in the process of continuous reform, the planned economy still influences and restrict the education system. The education concept and management concept of school leaders should also follow the trend of the times and stand in a higher perspective. They should constantly explore a scientific and effective education management system method that truly respects the law of life development. Nowadays teaching and education are usually disjointed during the teaching. Ignoring the life development of students, teaching just for teaching, without laying emphasis on the life development status of teachers themselves and the integration degree of teaching can directly affect the education and learning growth and life development quality of students. Most parents do not pay enough attention to family education and rely too much on school education. Without paying attention to parents' words and deeds, the children cannot develop healthy. Students have not formed a good environment of learning together, mutual growth of friends influence the cultural atmosphere. At present, each element exists some problems separately that affect the system overall educational target and constraints. Those various elements have no consensus about educational target concept. What's more, some of them are fragmented and influence each other interference. There's no doubt that we need to lay adequate attention from the perspective of system coordinated development so that the education system can trigger a systemic change.

\section{Analysis of the Action Mechanism of Coaching Technique on Education System}

The father of humanistic psychology, Carl Rogers says the ultimate goal of a person's life is to be himself. The final purpose of education is not to create identical products in an assembly line, but to support each life to live their most authentic self. Coaching technology is a scientific method system that cares for the essence of life and pays attention to the overall harmonious growth and development of life from inside to outside. Coaching technology emphasizes the significance of a human and truly supports self-exploration, self-development of accompanying people from the perspective of supporting life development, stimulates potential, dissolves interference, promotes effective actions to achieve life goals and live a better life.

Without the development and promotion of each core element, education system cannot achieve systematic coordinated development. What's more, the overall coordination among the core elements are also of great importance. Any serious problem of any one element will affect the goal and effect of education. Therefore, only by using scientific people-oriented coach technology system method to support core factors of education system and promote consensus building among the various elements, can we improve the quality of all elements of education system comprehensively. Through the above approaches, educational concept, educational ability of education system and the improvement of overall education culture can be realized. Meanwhile promoting the overall objective of education systematically will come true and the education system will play a positive and effective role to the students. Around the five core elements of education system, we will build a coaching technical model of the education system, objective analysis promoted development direction and trend of the education system. From school leaders, teachers, and parents of the education system to students, coaching techniques have an effective application in every group. 


\subsection{Coaching-Leader, Improving Mind Leadership in Driving Inner Strength}

As a leader, it will endure more external pressure than others, and there are also various challenges from the development of self-life. As the leader of educational institutions, it is also responsible for the responsibility of educating and cultivating talents. Therefore, the education leader's own educational management philosophy and his own life state not only have a direct impact on himself or his family, but also affect the life development of countless teachers and students, as well as the harmony of many families through the creation of school education concepts and cultural atmosphere.

The master of success, Steven Covey, putted forward that the true leadership is to be able to listen to your own voice, to embark on the path of living your own heart, and to support more people to listen to their inner voice and support them to live up to the way of their hearts. Therefore, the mind leadership of putting people first, focusing and inspiring internal driving force is the core literacy and ability that the leaders in the new era should have. As an education leader, it should first focus self on walking on the road of self-life growth, listening and practicing own voice. Then, it is also important to apply the experience on education management, to support the education institution to establish the educational philosophy of putting people first, putting heart first and supporting life development, so they can respect the unique value of each life, listen to the voices of each teacher and children, stimulate teachers' self-centered work value and drive, and stimulate the inner desire and motivation of children's self-learning and growth, supporting teachers and children to embark on the road of living a heart and living the value of life. These are the direction that education leaders should think and focus on.

A coaching education leader needs to firmly establish the thinking model that aims to educate people. First, it needs to deeply understand the nature and goals of education, set the development goals and core values of the school from the essence of educating. Then, actively exploring the advanced educational concepts and methodologies of applied science is also required, it should fully combine the desires of life development between teachers and students in the education process, closely focus on the overall goal of education, and fully provide the resource platform for teachers and students to realize their respective goals. As the result, it can create a better culture and atmosphere, stimulate team cohesion, achieve multi-win, and truly achieve the common growth of the education organization system.

The coaching learning training of mind leadership, as well as one-by-one coaching, is a strong support for the growth of the education leader's personal life. Leaders can carry out self-exploration with their coaches, listen to their voices, clarify their goals, resolve disturbances, improve their mental strength, and further enhance their self-life and external leadership through internal growth. It should be supported for education leaders to truly establish a new educational philosophy and idea of putting people first, putting heart first.

\subsection{Coaching-Teacher, Educating Students in Affecting Life}

The effectiveness of the intervention depends on the state of the intervener itself. Teachers are the direct and most important interveners and influencers in the development of students. Therefore, teachers' own life state, educational concepts, educational methods, and teacher-student interaction models are critical to the growth and development of students.

The purpose of educating is to support the growth of life, and education is the process of life affecting life. The role of teachers in the new era is no longer just a transmitter of knowledge and information. It is also the responsibility of teaching and educating, and is the guide, supporter and companion who support the growth and development of students' lives. Many teachers do not have a deep understanding of the nature of educational work, they attach importance to teaching and do not pay attention to educating. The separation between teaching and educating is an important reason why teachers can't find happiness and value in their work. It is also an important factor that affects teachers' self-life state and quality of life, affecting the effect of education and education. 
As a teacher of life development guides and supporters, it must first put self-life growth on the most important consciousness, and on the road of self-life development. Then they can constantly realize the development and breakthrough of self-life and solve the development of self-life, supporting the growth of more students. Such teachers can understand the individual characteristics and growth rules of each life. They are willing to believe that each student is inherently capable, so they can communicate with student equality rather than put themselves at a high position. They can listen to the students' inner voice and growth desire, support, encourage and accompany each student's personalized development and growth.

The systematic learning and practice of coaching technology can not only support teachers learn the professional knowledge, but also help teachers truly understand and focus on the nature and goals of education, paying more attention to the life development of students. Teachers should firstly pay attention to and promote their own life growth, and then apply their own beneficial method ideas to the work of teaching and educating. Teachers should also integrate teaching and educating organic, teaching for educating people and educating people in teaching. As the result, they can find the real focus in the education work, find the source of true happiness and value. At the same time, they can also use coach-style and high-quality dialogue skills to establish a good teacher-student relationship, promoting effective interactive communication and strongly supporting students' life growth.

\subsection{Coaching-Parent, Improving the Awareness of Love, the Wisdom and Ability of Love}

Family education is an important environment and influencing factor in the growth of children. Parents are also important interveners in the growth of children. Parents' life status, educational philosophy, and educational methods also directly affect their learning and growth.

Most parents have taken the role and responsibility even if they have not learned how to be a parent. Although the parents all over the world love their children, many parents unconsciously do things that control, intervene, and even harm the healthy development of their children in the name of love, including excessively worried, overly pampered, over-constrained, over-controlled and over-indulgent that are not conducive to the healthy development of children. These "excessive" actions are derived from the lack of understanding and respect of children's life characteristics and growth rules, generating a lot of unnecessary worry and anxiety. The main reason is the limitations of parents' self-life development and less confidence of the children's wisdom, bringing too much restraint and interference to the children's self-development, which affects their physical and mental health.

The root reason of family education is the life state of the parents, the relationship between husband and wife, the educational concept, and the educational method, which are important for the improvement and promotion of family education. It is necessary for parents to enhance their sense of love more consciously in the process of educating their children by learning the wisdom of love, improving the way of love, and reinforcing the ability to love.

The subject learning of coaching awareness of parents can support and guide parents to re-examine the way and effect of children's love. Parents should improve the wisdom of love, the awareness of love and the effect of love from the perspective of understanding and respecting the characteristics of life development, from the perspective of supporting themselves and children's life growth. In this process, parents began to pay more attention to the improvement of self-life quality, constantly promote the harmony of husband and wife relationship, and create more love environment and atmosphere for children. At the same time, parents begin to trust and respect the child's life growth characteristics, give children more freedom and space, and learn to use the coach's communication and dialogue skills to strengthen communication and interaction with children, establish good parent-child relationship, and maintain awareness of self-state and timely adjustment themselves. Finally, parents become a powerful support force for the growth and development of children's lives not only on physically, but also on spiritual growth. 


\subsection{Coaching-Student, Improving Self-Growth and Peer Support Ability}

In different stages of learning and growth, students will encounter various learning pressures and growing pains. It is often difficult to find solutions by themselves, so they get stuck in difficulties easily which may even affect their study as well as physical and mental health. In addition, student-faculty ratios in the education environment in China is generally high, therefore it is almost impossible for the teacher to pay deep attention to the growth process and inner troubles of each student in time. Thus, in the process of education, the improvement of students' self-growth ability and the peers' support play an integral role.

Students have learnt a lot of theoretical knowledge and professional skills during the process of learning and growing, but they seldom acquire the ability and methods of self-life growth and development. This results in high scores and low abilities, especially the lack of self-life development ability. Coach technology is both a concept and a method system which focuses on people's life growth and development. It advocates the goal oriented and positive focus mode of thinking, and the coaching method of self-awareness and self-dialogue, which support students to think and express more positively and adjust their state timely when encounter problems. What's more, it helps students look for all kinds of the solutions with oriented goal, try to mutual understand others, consider problems in multi-angles, fully use team's wisdom and resources, face up to difficulties, solve problems with positive attitude and grow up together. Thus, guiding student to not only understand and grasp the amount of coach technology concept and thinking mode but also learn the basic skills of self-coach is a beneficial practice, supporting students' personal growth and mutual help between classmates as well as the learning environment and atmosphere.

Coach technology's basic theory, applied courses and theme lectures can help students learn knowledge and expertise, expand the study about the ideas of self-life growth and development. Coach technology not only is able to support the development of the students' self-growth, but also assist students in forming collective consciousness and positive peer influence. Inspired by a coach technical thinking and method, students support each other and achieve common growth, and this has a very positive meaning and value for the growth of the students in the long run, even a lifelong development.

\subsection{Coaching-Culture, Building a People-Oriented Campus Culture}

The direction of transmission and construction of the educational concept and culture in education must be from top to bottom.

Firstly, education leaders should draw great attention to student education, starting from the real goal and essence of education and walking on the road of listening to and living their inner voice. What's more, leaders should take the lead in learning scientific concept and method system, playing a leadership, fully stimulating working enthusiasm, inspiring students' learning interest. Also, they should create a people-oriented educational atmosphere and campus culture, so that to promote growth for both teachers and students in the teaching process.

Secondly, teachers' team needs to pay more attention to not only promotion and development of their life, but also the appreciation and respect to students' unique traits. They have to influence students' life through their own action, integrate teaching and education and learn to use high quality dialogue coach technology to help students analyze and solve problems as well as achieve growth. In addition, teachers need to find the sense of meaning and worth in education and realize self-value pursuit, at the same time of effectively assisting students in growing up.

At the same time, the parents suppose to be more aware of the importance of family education for children' growth and development. Parents need to pay attention to family education of precept, using communication and dialogue with high quality, so that to strengthen the interaction with children, create more supportive parent-child relationship, give children more space to grow up. Also, they can cooperate with schools and teachers, give the children better understanding and support, and create a better growth environment. 
In addition, students can also learn some methods of the concept of life, growth and development, which helps to enhance the consciousness and the ability of self-development and self-growth. Gradually, they can learn to take responsibility for the development of their own growth, take positive interaction and form a mutual support, mutual cooperation and common growth peer-influence atmosphere at the same time with the help of the concept of coach method.

To sum up, in the education system, the systemic input of coach technology can effectively support the core elements to target objective consensus around education system and affect all the core elements and key roles from top to bottom to growth and development voluntarily. They can learn more scientific and effective education management concept, influence each other, support each other, form a resultant force, and jointly build a real people-oriented education idea and education culture with respect for life. Then the system can let each related member in the education institutions, including leadership, teachers, parents and students create greater education efficiency, achieve symbiosis and win-win and truly improve the achievement of education's overall goal of education. Thus it can be seen that the systematic input and support of the core elements of the system through coaching technology can promote the generation of psychological leadership, the improvement of teachers' and parents' ability of education, the co-construction of people-oriented education culture, and finally improve the effective output of education's systematic goals and achievements (See Figure 2).

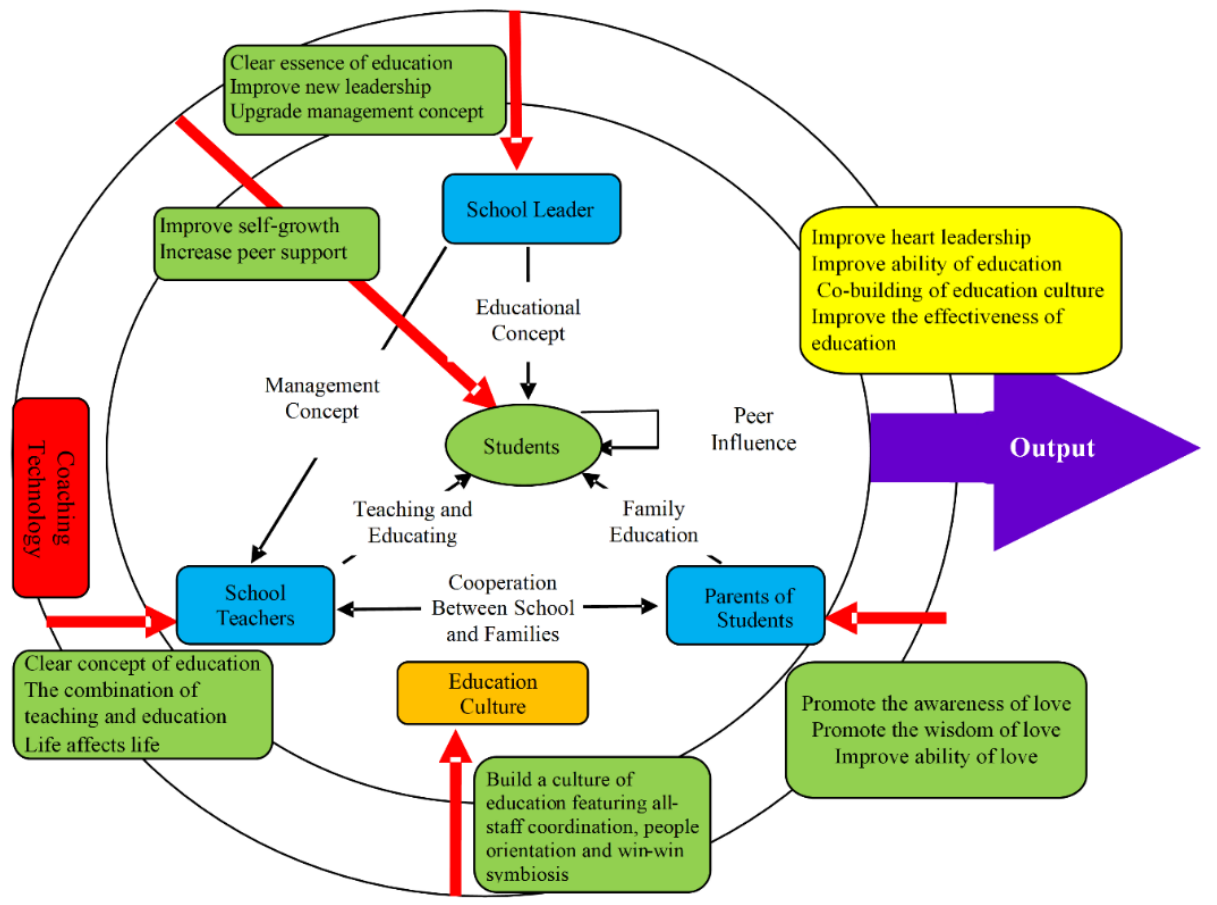

Figure 2. The mechanism of the action of coaching technology on the input and output of education system.

\section{Conclusions and Limitations}

In this paper, we analyzed the complex system characteristics of the education system by using the system theory method, analyzing the five core elements of the education system that influence the system education goal and the development status of these five core elements in detail as well as the relationships and interaction between the five core elements. With the continuous progress of the society, the traditional teaching mode cannot conform to the trend of social development, cannot meet the requirements of students, is not attractive to students, and is not conducive to stimulate students' learning enthusiasm. Coaching technology defines that everyone is willing to constantly surpass, realize and develop themselves. Everyone also has enough resources and ability to achieve the goals he or she requires and needs constant and reasonable guidance. Thus, it is scientific and feasible to use 
coaching technology in education system from the perspective of overall development. In this paper, we believe that the core concepts and methods of coaching technology can effectively support the overall coordinated development of the entire education system and the effective improvement of the system's educational goals through targeting the development of the five major factors and promoting the coordinated development of elements.

In theory, the remarkable effect of coaching technology in the field of management has gradually aroused the research interest of psychology, pedagogy and other related workers. Coaching technology originated from business management, but combined with education in school, which is undoubtedly a pioneering move. In reality, the combination of coaching technology and student education is the improvement and supplement of the original guiding ideology, which can improve the effect of coaching activities and make individuals grow better. This paper is a meaningful exploration and attempt to explore the overall coordinated development of the education system by using the system theory method, the application of coaching technology in education system is feasible to some extent, and it needs to be further verified and improved in more practical applications.

Author Contributions: All authors contributed to the paper. Y.O., Y.-S.S., and C.L. collected and organized data, and wrote the manuscript. Finally, Y.-S.S. acted as a corresponding author.

Funding: This study was supported by the Ministry of Science and Technology, Taiwan, R.O.C., under Grant MOST 107-2511-H-008-007 and MOST 107-2511-H-019-003.

Conflicts of Interest: Authors declare no conflict of interest.

\section{References}

1. Gao, L.; Qiao, X. The System of Ideological and Political Education from the Perspective of System Management Theory. Exploration 2014, 1, 149-152.

2. Chen, W. Model Construction and Structure Optimization of Higher Vocational Education System-Based on Systematic Perspective. Educ. Exam. 2011, 5, 65-69.

3. Gou, B. Systematic Analysis of School Education. Exp. Teach. Instrum. 2016, 1, 69-70.

4. Li, Z. Analysis of the Dynamics of Entrepreneurship Education in American Universities from the Perspective of System Theory. J. Northeast Norm. Univ. 2017, 5, 197-202.

5. Meng, X.; Hou, L. College Academic Style Construction from the Perspective of System Theory. J. Liaoning Inst. Soc. 2007, 3, 69-70.

6. Liu, C.; Du, S. The Effectiveness of Moral Education from the Perspective of System Theory. J. Jiangsu Inst. Educ. Soc. Sci. Ed. 2006, 1, 14-16.

7. Wang, Z. A Path of Community Education Reform and Development under the Perspective of System Theory. Core China Adult Educ. 2017, 21, 155-157.

8. Zou, S. Research on the Construction of Methodology System of Ideological and Political Education-From the Perspective of Complex System Theory. Ideol. Theor. Educ. 2016, 1, 49-53.

9. Xing, X. Analysis of the Modern Transformation of Ideological and Political Education from the Perspective of System Theory. Ideol. Educ. Res. CSSCI Peking Univ. Core 2016, 9, 30-34.

10. Li, H. An Effective Way to Develop the Function of Ideological and Moral Education-From the Perspective of System Theory. Res. Political Teach. Middle School Late 2014, 8, 36-38.

11. Jiang, L. The Formation of Individual Morality and Subjective Moral Education-Based on the Perspective of System Theory. J. Taiyuan Univ. Technol. Soc. Sci. Ed. 2013, 5, 13-16.

12. Wang, F.; Jia, M. Enlightenment of coach technology on education concept of ideology and politics. J. Langfang Norm. Univ. 2013, 6, 123-125.

13. Yang, A. School Mental Health Education from the Perspective of System Theory. Psychol. Health Educ. Prim. Second. Sch. 2013, 16, 44-45.

14. Zhong, X. Application of coaching technology in improving college students' innovation and entrepreneurship psychological quality. J. Shenyang Univ. 2008, 20, 604-607.

15. Sun, W. Research on Family Education Based on System Theory. J. Hebei Norm. Univ. Educ. Sci. Ed. 2013, 6, 29-34. 
16. Cui, Q. The Application of System Theory in College Students' Life Education. Cult. Educ. Mater. 2013, 21, 138-139.

17. Jiang, Y. Higher Education Management from the Perspective of System Theory. J. Xinyang Norm. Univ. Philos. Soc. Sci. 2006, 5, 66-67.

18. Yang, J.; Zhang, Y.; Li, M.; Zheng, S.; Ding, Y. Research on the Influencing Factors and Optimization of College Students' Life Education. J. Zhejiang Vocat. Coll. Commun. 2017, 1, 74-77.

19. Lin, G. Examine and Return the Quality of Life of Educators. Educ. Prac. Res. Theor. Ed. 2017, 4, 4-6.

20. Zhao, H.; Liu, W. Coaching leadership, dual learning and team creativity: The moderating effect of team learning goal orientation. Foreign Econ. Manag. 2008, 40, 66-80.

21. Zhu, X. Is life education difficult? In fact, teachers are doing this every day. Teach. Constr. 2017, 4, 43-47.

22. Chen, J. Research on the application value of coaching technology in ideological and political theory courses in colleges and universities. Contemp. Educ. Prac. Teach. Res. 2018, 10, 39-40.

23. Chen, R. Life Education: A Blind Spot on School Education and Family Education. Basic Educ. Forum 2012, 6X, 18-19.

24. Liu, D. China's education reform must start from the source. Decis. Inf. 2017, 16, 10-13.

25. Wang, Z. How to be a qualified parent in the new era. China Teach. Dly. 2018, 12, 3.

26. Zhang, N. Enlightenment of meng mother's family education concept on modern family education. J. Shaanxi Radio Telev. Univ. 2018, 04, 50-53.

27. Chen, Z. Influence of peer group environment on adolescent development. J. Ningbo Univ. 2004, 5, 61-64.

28. Zhao, J.; Yan, B. Differences in parenting style and achievement motivation between only-child and non-only-child parents of high school students. Chin. J. Health Psychol. 2008, 10, 1598-1600.

29. Gao, L. The prosperity of education in China. Educ. China 2018, 12, 1.

(C) 2019 by the authors. Licensee MDPI, Basel, Switzerland. This article is an open access article distributed under the terms and conditions of the Creative Commons Attribution (CC BY) license (http:/ / creativecommons.org/licenses/by/4.0/). 